\title{
La connotación en la invención léxica cadia cuento «La Cadia» de Elisa Chimenti
}

\author{
María Katjia Torres Calzada ${ }^{1}$ (D)
}

Accepted: 15 November 2021 / Published online: 18 January 2022

(c) The Author(s) 2022

\begin{abstract}
This article analyses, from the perspective of lexicological research proposed by Georges Matore (1948), the witness-word included in the title of the short story «La Cadia». The starting hypothesis is that the linguistic sign cadia, as a lexical invention derived from the Arabic legal term and the keyword $q \bar{a} \bar{d}^{i n}$ (qadi), has a communicative function of epigraph, typical of the discursive superstructure of the medieval Arabic and Islamic khabar that the author applies, as a traditional vehicle for transmitting the legitimizing role of Islam. We conclude by verifying the hypothesis that cadia connotes the institutionalization of male authority in Islam, at the expense of the inferior status of women.
\end{abstract}

Keywords Lexicology $\cdot$ Langue pataouète $\cdot$ Witness-word · Epigraph

« Je te raconte,

Ne crains rien, ne crains pas les génies. " Elisa Chimenti, Èves marocaines, 1934.

\section{Introducción}

En 2009, Editions du Sirocco \& Senso Unico Edition reedita cinco obras de la polígrafa nacida en Nápoles, Elisa Chimenti (1883-1969) ${ }^{1}$, conocida como la Donna mediterranea ${ }^{2}$, entre las cuales se encuentra la colección de cuentos Èves

\footnotetext{
1 Las investigadoras Mirella Menon y Maria Pia Tamburlini permitieron rescatar a la autora del olvido, con dicho proyecto. En 1998, elaboran el informe sobre los avances de su investigación titulado Elisa Chimenti. Archivio, https://www.elisachimenti.org/texte/biographie_elisa_doc/biographie_elisa_doc1. pdf, centrado en su biografía documentada y, en 2010, por iniciativa del secretario literario personal de Elisa Chimenti, Ahmed Benchekroun, y la de su esposa, Olga Benchekroun, se crea la Salle Elisa Chimenti en la ubicación de la Fondation Méditerranéenne Elisa Chimenti, con sede en el antiguo Palais Moulay Hafid de Tánger.

${ }^{2}$ La Direzione Generale de la Cooperazione allo Svillupo del Ministerio degli Affari Steri. https://www. elisachimenti.org/biographieS.html financia, en 1997, el proyecto Donne Mediterranee.
}

María Katjia Torres Calzada

mtorres2@us.es

1 US: Universidad de Sevilla, Sevilla, Spain 
marocaines $^{3}$ (Chimenti, 2009: 434-601), que incluye el titulado «La Cadia» ${ }^{4}$ (434-439).

Es el primer cuento ${ }^{5}$ de una colección de doce ${ }^{6}$ que constituye una muestra del dialecto regional del francés «pied-noir» o «pataouète» (Bénouis, 1974: 581), al recoger niveles de enunciación oral de personajes magrebíes pertenecientes a estatus socioeconómicos diversos que reflejan la fonología propia y las innovaciones sintácticas de la deformación involuntaria del francés norteafricano culto.

Cadia es una diversificación lingüística -diacrónica, diastrática, diafásica y diatópica-, fruto de la invención léxica por derivación del término jurídico islámico medieval $q \bar{a} \underline{d}^{\text {in }}$ (cadí o juez) (Milliot, 1953; Schacht, 1964) que permite realizar un análisis sociolingüístico de la connotación de su referente. Este participio activo femenino árabe, con funciones sintáctica de nombre calificativo y comunicativa de apodo o apelativo $\left(\right.$ laqab) ${ }^{7}$ (Thomas de Antonio 1989: 343-344), nos sitúa ante una hipotética irrealidad institucional del Dār al-islām (territorio del islam) -por inexistente, en la teoría y en la práctica en lo que designa el término cadia, no tanto así en la institución ${ }^{8}$ con la que está vinculada-, tanto en época de la autora como en la que está ambientado el cuento, según las fuentes históricas conservadas (Gaudefroy-Demombynes, 1946), los tratados jurídicos sobre las normas de conducta de los jueces o $a d a b$ al-qāậ/ $\bar{a} d \bar{a} b$ al-quḍat (Fyzee dic. 1964: 406) y los repertorios bio-bibliográficos dedicados a los sabios del islam árabe (ilm al-riŷāl y tabaqāt)

\footnotetext{
${ }^{3}$ La primera edición corrió a cargo de André Éditions Internationales y fue publicada en Tánger, en 1934.

4 Elisa Chimenti ofrece la transliteración simplificada, en grafía latina, del árabe clásico /qāẹlya/, siendo la /q/ sorda, oral, uvular, velar y oclusiva y la /ḍ/ sonora, oral, dental y oclusiva. Conforme al sistema de transliteración de las revistas científicas al-Andalus y Miscelánea de Estudios Árabes y Hebraicos. Sección Árabe-Islam.

5 Reproducido en el anexo final, conforme a la edición utilizada para este estudio.

${ }^{6}$ Los once restantes son «Oum-Hani» (440-444), «Chez la maalema» (445-450), «Histoire du fquih de Tandja el-Balia» (451-454), «Maléfice» (455-461), «Le premier diamant» (462-464), «Les deux trésors» (465-480), «Vengeance d'Aïssaoui» (481-510), «Saadia» (511-519), «Les bracelets algériens» (520-534), «Si Ahmed el-Jebli» (535-589) y «Mennouch» (590-601).

7 El término laqab designa el cuarto componente del nombre propio clásico árabe de persona: kunya (patronímico), ism (nombre personal), nasab (genealogía), laqab (apodo) y nisba (nombre de origen). Hace referencia al nombre de profesión o a una cualidad positiva o negativa que hace famosa a la persona o a un acontecimiento con el que se le asocia.

${ }^{8}$ La institución del cadiazgo como tal, se origina en la designación personal de un juez por parte de un califa. En lengua árabe, recibe el nombre de la persona que ejerce la función de impartir justicia el $q \bar{a} d \underline{\bar{l}}$ $l$-quḍat, es decir, el juez de jueces o juez supremo. Fue creada por el califa 'abbāsī Hārūn al-Rašīd, en el siglo IX d.C.
} 
(Ávila-Marín, 1997; Lachiri, 1993, 2002), por citar solo las fundamentales para el fin de este estudio.

No obstante, Elisa Chimenti, por medio de la ficcionalización literaria, siguiendo la tradición del cuento popular oriental (qișsa) ${ }^{9}$ (Allen, 2011; Sobh, 2002) y la del racconto ottocentesco europeo (Pellizzi, 2002), da al apelativo cadia, una connotación que «détermine» (Matoré, 1948: 10) un concepto con el que, paradójicamente dada su supuesta inexistencia, debe estar familiarizado el receptor, para que se consiga el objetivo perseguido: trasvasar «sans transition, presque [...] d'un moyen âge retardataire à la vie moderne» (Chimenti 209: 605), la problemática social y el pensamiento del momento (Del Moral, 1994: 102): la escenificación de la institucionalización islámica de la autoridad masculina.

La diversidad sociolingüística (López Morales, 2004; Romaine, 1996), antropológica, religiosa, socio-económica, ideológica y cultural del cuento «La Cadia» requiere de un receptor alfabetizado y/o aculturado en la lengua francesa, conocedor de las tradiciones del judaísmo y del islam y con nociones, al menos, de la lengua y la producción literaria en árabe estandarizado, en árabe medio ${ }^{10}$ (Blau, 1965, 1981: 187; 1988; Ferrando, 2001: 135 y 147), en judeo-árabe y en dialecto marroquí estandarizado o dārî̀a. Este conocimiento específico esencial posibilita la comprensión de la relevancia tanto de la invención léxica como la de su referente, dado que reflejan una realidad histórica concreta que afecta a las mujeres de la cuenca mediterránea magrebí: el estatus de inferioridad institucional de la mujer en el islam (Tillion, 1966).

Conforme a la propuesta lexicológica de Matoré (1948), cadia es una derivación de una palabra clave (mot-clé) $q \bar{a} \underline{d}^{i n}$, que sintetiza la civilización del islam en la institución del cadiazgo (Milliot, 1953; Schacht, 1964) medieval y moderno -desde el siglo VII d.C. hasta las primeras décadas del siglo XX-, y es utilizada, retroactivamente, para trasladar al lector a un pasado remoto, casi legendario, en un escenario simbólico para el islam marroquí como es su capital espiritual: la ciudad de Fez. De esta forma, la autora transforma esta invención léxica en una palabra testigo (mot-témoin) al incluirla en el campo lexicológico del cadiazgo (qaḍ̂-l-quḍāt) (Gaudefroy-Demombynes, 1946).

\footnotetext{
${ }^{9}$ La tradición del cuento oriental (árabe, persa y turco) transmitida por la vía de la traducción y/o adaptación al francés, a través de las colecciones de cuentos tales como Les Mille et Une Nuits, Les Cent et Une Nuits, Les Mille et Un Jours: contes orientaux, Quarante Vizirs, Sept Vizirs, Kalila et Dimna o Antar, entre otras, por orientalistas de la talla de Antoine Galland, Maurice Gaudefroy-Demombynes, Jacques Collin de Plancy, Denis Dominique Cardonne, Antoine-Isaac Sylvestre de Saci, René Basset, Henri Laoust, Jean-Adolphe Decourdemanche convive con un acervo no del todo explorado de historias breves, anécdotas y cuentos populares locales que han servido de herramienta a gramáticos, historiadores, moralistas, teólogos e incluso juristas. En lo que respecta a la tradición cuentística marroquí, preferentemente beréber en sus variantes geolectales y sefardí, destaca la labor de especialistas como Françoise Légey, Khati Cheghlon, Gustave Mercier, Jean Delheure, Samuel Léonard Biarnay, Mohammed El Fasi, Emile Dermenghem y la propia Elisa Chimenti. Únicamente, además de nuestra autora, solo consta que tenga una colección publicada Françoise Légey (París, 1926), conocida como la «toubiba» o médica jefa de la Maternité indigène de Marraquech que funda en 1912.

${ }^{10}$ Dentro de la variante del árabe clásico como koiné gramatical sistematizada en el siglo VIII d.C., en las fuentes árabes, se incluyen desviaciones gramaticales del mismo denominadas árabe medio -del término Middle Arabic acuñado por Joshua Blau (1965)-, que designa la variedad urbana practicada por la población arabizada no procedente de tribus árabes genuinas.
} 
Analizamos esta invención léxica, partiendo del supuesto de que el «vocabulaire est 1'expression de la société» (Matoré, 1948: 9) en virtud de que la palabra «opère une cristallisation du concept» (10) y permite el estudio del vocabulario por ser el que expresa «l'ensemble des activités humaines à une époque déterminée» (10).

Por ello, mostramos la importancia del signo lingüístico cadia, tratando los tres siguientes aspectos esenciales:

(1) La poliglotía y la ecléctica formación cultural de la autora,

(2) La relevancia del género literario elegido y las innovaciones discursivas que presenta el cuento y

(3) El análisis sociolingüístico de la invención léxica cadia, considerando estos dos aspectos previos, dada la transcendencia que adquiere en contexto islámico, en general, y el marroquí, en particular.

La conclusión a la que llegamos es que la autora recurre a esta invención léxica, convirtiéndola en palabra testigo con connotación asociada a la denotación de la palabra clave de la que deriva y que el cuento escenifica, es decir, la personificación de la desigualdad institucional entre hombres y mujeres en el islam (Ascha, 1989: 47-52). Además, posee un valor apotropaico anunciado en el encabezamiento del cuento $-\ll$ Je te raconte, Ne crains rien, ne crains pas les génies» (Chimenti, 2009: 434)-, puesto que determina a una mujer con una necesidad emocional de hallar seguridad ante la incertidumbre, con el fin de alejarse de una situación fuera de su control: la contingencia de ser coesposa legal en contexto islámico medieval.

La condición de la mujer casada, según la institución del matrimonio islámico o nikạh (al-Gazālī 1963; 1989; Bouhdiba, 1975; Bousquet, 1966: 20; Quṭb, 1960), que es «le contrat par lequel on acquiert l'appareil générateur ( $a l$-bud $\left.d^{\star}\right)$ d'une femme, dans l'intention d'en jouir» (Ascha, 1989: 52), no corresponde más que a uno de los dos procedimientos a través de los cuales se le permite al hombre tener relaciones con mujeres «-l'autre étant le concubinage avec les femmes esclaves-» (52), es compatible legalmente con el primero.

La feminización de la palabra-clave marca una transgresión literaria frente a la normalización del estatus de inferioridad de la mujer en el islam, al escenificar, en un formato innovador del género narrativo del cuento, un tema tradicional: la autoridad del hombre (qawāma) ${ }^{11}$ (Cortés, 1999: 36), a través de la obediencia al marido y la sujeción a la tetragamia. Permite considerar que estamos ante una crítica del estatus de superioridad del hombre sobre la mujer en el islam que hace comprensible el uso de la astucia (kayd) ${ }^{12}$ (Cortés, 1999: 89), como único recurso para contrarrestar una situación legal de inferioridad irrevocable y de desigualdad entre hombre y

\footnotetext{
11 Aleyas 34 de la azora IV «Las mujeres»: «Los hombres tienen autoridad sobre las mujeres en virtud de la preferencia que Dios ha dado a unos más que a otros y de los bienes que gastan. Las mujeres virtuosas son devotas y cuidan, en ausencia de sus maridos, de lo que Dios manda que cuiden. ¡Amonestad a aquéllas de quienes temáis que se rebelen, dejadlas solas en el lecho, pegadles! Si os obedecen, no os metáis más con ellas. Dios es excelso, grande».

${ }^{12}$ La tradición islámica identifica esta astucia en términos despectivos con la argucia propia de la naturaleza de las mujeres, a través de la historia de José recogida en el Antiguo Testamento y que El Corán adapta en la azora XII «Yūsuf», aleya 28, y que reza así: «Y cuando vio que su camisa había sido desgarrada por detrás dijo: «Es una astucia propia de vosotras...Es enorme vuestra astucia».
} 
mujer (Ascha, 1989: 31): «Les traditions islamiques recourent au kayd à chaque fois que la femme essaye de prendre une initiative quelconque ou bien qu'elle montre une lueur de malice ou de raison à laquelle l’homme ne s'attend pas».

Esta desigualdad se traduce, en virtud de su autoridad (qawäma) y su preeminencia o grado (darâya) (Cortés, 1999: 21) ${ }^{13}$, en obediencia al hombre, quien disfruta, por la institución del matrimonio, del derecho de amonestar o corregir a su esposa. El personaje del cadí representa los valores ideales requeridos en la conducta de un juez musulmán en justo equilibrio con los afectos suscitados por su esposa en él.

El final abierto, en apariencia inconcluso con respecto a la superestructura comunicativa del jabar (Ávila-Marín, 1997; Rodríquez Mediano, 1995; Wensinck, 1978) o noticia bio-bibliográfica árabe medieval, plantea interpretaciones contradictorias, debido a la estructuración en oposiciones proporcionales propias del género narrativo del cuento que la autora innova. Paralelamente, adapta formatos narrativos occidentales y orientales tanto clásicos como contemporáneos, a través de la inventiva y del juego (Marchetti, 2017: 144) característicos de su estilo, e involucrando al lector dentro de la actividad creadora de la narración en calidad de participante indispensable en la resolución del conflicto propuesto.

\section{Elisa Chimenti (Nápoles, 1883-Tánger, 1969): esbozo biográfico de una poliglotía}

Elisa Chimenti es hija de la sarda Maria Luisa Ruggio (Rughò o Ruggiu) Conti ${ }^{14}$ (Nápoles, 1859-Tánger, 1943) (Elías de Tejada, 1960: 250; Pilia, 2013: 385-588), y del napolitano Rosario Ruben Chimenti (Nápoles 1850-Tánger 1906/7) (Tamburlini, 1998: 91-93) ${ }^{15}$.

Según la información facilitada por Maria Pia Tamburlini (1998), biógrafa oficial de Elisa Chimenti, su acervo lingüístico constatable es de más de diez lenguas (Chimenti, 2009: 873), siendo bilingüe en francés e italiano (872), esta última su lengua materna. En la escuela de la Alliance Israélite Universelle (Laskier, 1983) de Túnez

\footnotetext{
13 Aleya 228 de la azora II «La vaca»: «Ellas tienen derechos equivalentes a sus obligaciones, conforme al uso, pero los hombres están un grado por encima de ellas».

14 Cofundadora y directora de la Nuova scuola en Tánger (1914), germen del futuro sistema educativo italiano en Marruecos. Elisa Chimenti, en una nota autobiográfica en la inédita A Fairy Tale http://www. elisachimenti.org/texte/biographie_elisa_doc/doc_bio2/50/50_fonds_elisa.pdf indica que su madre, hija de Giovanni Battista di Sassari y de Clemence Cherloneix de París, es descendiente del virrey de Cerdeña Domenico Alberto Azuni (1749-1827).

15 Escritor y cantante, garibaldino convencido, «dottore in medicina» y «professore allá facolta di Napoli», es hijo de Nicola y Elisa Cavallo y, según recoge Elisa Chimeni en A Fairy Tale y biznieto del célebre físico inglés Lord Tiberio Cavallo (Nápoles, 1749-Londres, 1809). Con su esposa, Maria Luisa Ruggio, tuvo tres hijas Maria Esther Clemence, Maria Giulia Elia Clemence y Maria Dina Lorenzina, y un hijo, Ricardo Ermanno Renato Cesare. Todos nacidos en Túnez, salvo la más joven, Maria Dina, que nació en Tánger. Tenía una relación extramatrimonial con otra mujer, Maria Giraldi, con la que tuvo un hijo llamado Roberto (Túnez 24.09.1884-Tánger 21.02.1937), integrados en el mismo núcleo familiar. El dato de ejercer la profesión como profesor en la Facultad de Medicina de su ciudad natal, lo ofrece su biznieta Danielle Chimenti, en 1997.
} 
capital, aprende el hebreo y el árabe de los textos sagrados, de la mano del eminente rabino El'azar Farḥī ${ }^{16}$ (Túnez, 1851-1930) (Bunis et al., 2002; Tobi, 2010), quien dejará una marcada influencia en su posterior obra literaria y educativa (Chimenti, 2009: 604, 872). Hasta el año 1899, fecha en la que la familia abandona Túnez, Elisa Chimenti, adquiere el francés norteafricano culto y el coloquial denominado piednoir o pataouète, el judeo-árabe y el árabe dialectal urbano de Túnez capital. La salida del país responde al llamamiento del sultán marroquí Moulay Hassān a Rosario Ruben Chimenti para entrar a su servicio como médico personal (15). La familia Chimenti se asienta en la ciudad de Tánger, donde Elisa Chimenti entra en contacto con el lissan franji tangérois y otros geolectos, gracias a que acompaña a su padre en el ejercicio de su profesión a los harenes domésticos urbanos y rurales de toda condición socioeconómica, donde tenía vetado el acceso, por su condición de hombre.

Continúa con su formación académica plurilingüe en una farmacia que hacía las veces de «une école sui generis» (872), la conocida como farmacia Totier: «un lieu de rencontre d'intellectuels espagnols, italiens, français et anglais», destinado a los hijos de europeos residentes y de los notables locales (González, 2010: 30-110; Miège, 1962; Paye, 1992).

Elisa Chimenti afirma haber realizado, en la primera década del siglo XX, una diplomatura en Letras en Alemania, pero no queda constancia de ello, debido a la pérdida del título, una vez finalizada la Primera Guerra Mundial (2009: 873). En la segunda década del siglo XX, publica dos obras en alemán, hoy consideradas desaparecidas, Meine Lieder (1911) y Taitouma (1913) y artículos de prensa en el periódico Lokal Anzeiger -posiblemente, de Berlín-, según el curriculum vitae redactado por ella misma (873).

En 1912, se casa con el conde de origen polaco y nacionalizado alemán, Friederick Dombrowski ${ }^{17}$, obteniendo, también, la nacionalidad alemana y su apellido ${ }^{18}$ (Menon \& Tamburlini, 1998: 99-100). Con él recorre Europa -Portugal, España, Inglaterra, Holanda, Alemania, Polonia y Rusia-, permitiéndole diversificar su acervo lingüístico a su regreso a Tánger, en ese mismo año. $\mathrm{Su}$ marido retorna a Alemania a causa de sus graves trastornos mentales, pero parece que decide alistarse en el ejército, para participar en la Primera Guerra Mundial, momento en el que se le pierde la pista (Menon \& Tamburlini, 1998: 99). A partir del año 1912, no consta que Elisa Chimenti realizase traslados a otros países fuera de Marruecos con

\footnotetext{
${ }_{16}$ El'azar (Eliezer) Farhị erudito de la élite judía tunecina, responsable, junto con Hai Sitrūk, de la edición en judeo-árabe de Sīrat Dāt al-Himma, impresa en Túnez (1890), cuyo manuscrito (MS Arabe 3480-51 - ss. XVII-XVIII) se encuentra en la Bibliothèque nationale de Francia. Intelectual extremadamente preocupado por la reforma educativa en el seno de la comunidad judía, lidera la corriente denominada haskala o renacimiento, equivalente a la nahḍa árabe e islámica, de principios del siglo XIX.

17 Hijo de Friederick Dombrowski y Bertha Koette. Nacido en la Polonia ocupada y súbdito de Dirschau (Kreis Dirschau, Ostpreussen). La ceremonia religiosa se celebra en la Iglesia de la Purísima Concepción de Tánger el 8 de agosto de 1912. En la noche de bodas, intenta estrangular a Elisa Chimenti, en una de sus crisis mentales, provocando su internamiento en un hospital psiquiátrico en Dziehanka, según comunicación del alcalde de Samotschin (Bonn, Alemania), y causando que la familia política de Elisa Chimenti, rompiera todo contacto con ella, quien obtendrá el divorcio, el 18 de marzo de 1924.

18 En su pasaporte alemán consta como Elisa Chimenti Dombrowski.
} 
documentación expedida por las autoridades marroquíes, que la consideran italiana, pese a su recién adquirida nacionalidad alemana ${ }^{19}$ (Menon \& Tamburlini, 1998: 100).

En 1914, funda con su madre la Scuola nuova ${ }^{20}$, en Tánger, donde trabajará hasta 1927/8, año en el que será licenciada de su puesto de maestra, por su rechazo a adherirse al régimen de Mussolini (Chimenti, 2009: 876). Esta medida la fuerza a trabajar, durante varios años, en otras instituciones educativas de la misma ciudad. En la Hohe Deutsche Schule, será maestra de lengua alemana y en la École Libre Musulmane, fundada en 1935 ${ }^{21}$ (Benhlal, 2005: 167-201; Cañete Aranda, 1998; Rivet, 1999) dirigida por su amigo, el pensador y reformista político Abdallah Guennoun, donde impartirá árabe clásico, siendo la única europea y mujer que enseñe a los futuros doctores coránicos del país, recibiendo el honorable apelativo de fquih (Menon \& Tamburlini, 1998: 92) o fquia (doctor o doctora en ciencias coránicas) (Chimenti, 2009: 876).

Hasta 1934, año de la publicación del cuento «La Cadia», su acervo lingüístico y cultural refleja, a sus 51 años de edad, el mestizaje y la hibridación en su dominio y práctica de lenguas dispares que cristaliza en una realización particular del lissan franji o parler tangérois «qui découle directement de récits oraux africains» (Chimenti, 2009: 879) constatable en su obra editada e inédita (https://www.elisachime nti.org/oeuvres_inedites.html) y que pudiera ser considerada una manifestación local de una «nouvelle lingua franca» (879; Mur, 2020) ${ }^{22}$.

Desde la constancia documentada del testimonio más antiguo conservado en el Contrasto della Zerbitana, (s. XIV d.C.), hasta la publicación del estudio más reciente (Dakhlia, 2008), pasando por el anónimo Dictionnaire de la langue franque ou petit-mauresque suivi de quelques dialogues familiers et d'un vocabulaire de mots arabes les plus usuels, à l'usage des Français en Afrique (1830) y el esencial estudio de Hugo Schuchardt (1909) «Die Lingua franca» ${ }^{23}$, escasas son las muestras de diversas realizaciones de lingua franca conservadas por escrito y tomadas de viva voz en ámbitos domésticos no vinculados con los tres tradicionalmente

\footnotetext{
19 Según Le Journal de Tanger (26.12.1981) su nacionalidad italiana fue puesta en duda al confirmar la Embajada de Alemania en Marruecos la alemana, incluso, tras la liberación de Polonia.

${ }^{20} \mathrm{La}$ escuela pasa a manos de la Associazione Nazionale per il Soccorso dei Missionari all'Estero (ANSMI) https://conscasablanca.esteri.it/consolato_casablanca/it/la_comunicazione/palazzo_istituzioni_ italiane_tangeri.

21 Institución educativa nacionalista creada, como el resto de las insertas en la acción del nacionalismo urbano árabe e islámico (1921-1925) a favor del sultán, con el fin de frenar la política educativa beréber de las autoridades francesas, iniciada en 1915, centrada en aislar a la población beréber no arabófona y poco islamizada, para someterla a un proceso de aculturación y naturalización que permitiera ocupar el país rápida y de manera efectiva.

${ }^{22}$ La conclusión de investigación que valida tal hipótesis está recogida en la memoria Sociedades Plurilingües: Elisa Chimenti, última representante documentada del lissan franji o lingua franca mediterránea magrebí, realizada por D. Juan Andrés Mur Márquez en el Doble Máster en Estudios Lingüísticos, Literarios y Culturales (MELLC) de la Facultad de Filología de la Universidad de Sevilla (2019/2020).

23 Según Schuchardt, es un pidgin de base lexical francesa influenciado por el árabe y por la lingua franca mediterránea - o Vermittlungssprache o Handelssprache (lenguas pidgin y jergas) que sus hablantes estimaban como lengua vehicular para hablar con la lengua del otro, es decir, francés y árabe, respectivamente.
} 
documentados: comercio, esclavitud y cautiverio por guerra, como sucede con la obra de Elisa Chimenti, en general y, en particular con «La Cadia». Este cuento, por lo tanto, constituye una muestra de la variante del francés norteafricano culto más occidental del territorio bajo la francofonía, en su realización tangerina y con la influencia del diverso acervo lingüístico de la autora.

\section{Resumen ilustrativo del cuento para la comprensión de la connotación de la invención léxica «Cadia»}

Este cuento, ambientado en la Fez medieval, escenifica la moraleja del proverbio

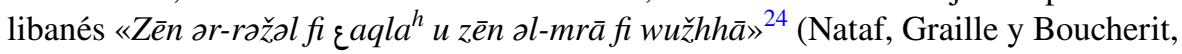
2002: 213), que la autora traduce como «La beauté de l'homme est dans son intelligence et l'intelligence de la femme est dans sa beauté» (Chimenti, 2009: 435). Con él pretende mostrar, a través del protagonista, el cadí $S i^{25}$ El-Arbi, la imposibilidad, por imperativo coránico (subapartado 4.1.) de encontrar relaciones entre hombres y mujeres, en un plano de igualdad/paridad/equidad. La relevancia lexicológica de la palabra testigo «La Cadia» reside en la connotación del laqab en el marco de la institucionalización islámica de la autoridad masculina.

Si El-Arbi desposa a Lalla ${ }^{26}$ Zouleima El-Arbi, hija de un «ouzir» (ministro del sultán), conocida por su laqab, dada su profesión y vinculación conyugal. Sus conciudadanos hombres, no sin cierto sarcasmo, le dan el título honorífico de «adila» (justa) (435), por considerarla una chaqia o «malhereuse», según aclara la autora/ narradora que la acuñación popular de este apelativo recibe: «Le mot féministe ${ }^{27}$ n'étant pas encore connu c'est ainsi qu'on nommait les femmes aux idées avancées» (435).

Entre los hombres de su comunidad, especialmente, entre los ulemas, esta unión conyugal es motivo de burla, por entender que «la science des femmes manquait de profondeur, qu'elle était toute de surface, qu'un cerveau féminin était incapable d'invention [Ô candides et naïfs oulama !] et même de perfectionnement» (434-435). No obstante, a Si El-Arbi solo le valen las buenas cualidades de su esposa, quien, a su vez, es de la opinión de que «les hommes manquaient de subtilité et de discernement, et qu'ils se laissaient influencer plus facilement que les femmes». Por su

\footnotetext{
${ }^{24}$ El proverbio resume, en esencia, la trama del cuento que no es otra que la superioridad del hombre frente a la mujer, conforme a la tradición islámica. Las autoras lo explican en los siguientes términos: «Quand, dans un ménage, la femme est belle et que 1'homme est laid, on dit ce proverbe en guise de consolation. Également pour marquer le côté matériel [sic] de la femme, et la supériorité de la spiritualité de 1'homme. La beauté de l'homme est dans son caractère, celle de la femme, dans son physique. La première est assurée de durer plus longtemps que la seconde» (2002: 213).

25 En cursiva en el original. Forma abreviada, muy común en dialectal marroquí, del título de tratamiento Sayyid, en árabe clásico/medio/estándar, equivalente a Don o Señor.

26 En cursiva en el original. Título de tratamiento en dialectal marroquí y en buena parte del mundo árabe e islámico, que equivale a Doña o Señora.

27 Está documentado que la primera persona que utiliza el nombre «féministes» como forma de reivindicación es la sufragista francesa Hubertine Auclert (1848-1914), en una carta publicada en el número 64 del periódico La Citoyenne (04.09-01.10.1882).
} 
parte, las mujeres de su comunidad, conforme a la tradición islámica, opinan que el conocimiento «vaut mieux que les richesses et le savoir est un plus grand trésor que les diamants et les perles» (434). Si El-Arbi, no obstante, no se queja de la inteligencia de su esposa Lalla Zouleima y muestra indulgencia con sus defectos.

Tras terminar ambos su jornada laboral en el tribunal, acostumbran a conversar, en la tranquilidad del hogar, sobre temas relacionados con la práctica de su profesión, entre los cuales, el cultivo de la ecuanimidad y del sentido de justicia. Si El-Arbi, al respecto, considera que las mujeres, al moverse por el mandato de su corazón y no de su cerebro, al contrario que los hombres, son, connaturalmente, injustas. Lalla Zouleima sostiene, no obstante, que la imparcialidad masculina se desvanece ante la seducción de cualquier bello rostro de mujer. Para lograr salir de la diatriba, Si El-Arbi decide apostarse con su esposa un manuscrito de valor incalculable frente a un humilde plato de cuscús, recurriendo a una argucia para demostrarle a su esposa lo errado de su criterio.

Si El-Arbi, pasados unos días, le comunica la llegada de su cheriqua (coesposa legal) Noufissa y le ordena preparar la dekchoucha (cámara nupcial) para la inminente boda. Lalla Zouleima, a la llegada de la aarousa (novia prometida), decide retirarse a su cuarto, dolida por la afrenta de su esposo, alegando enfermedad, para evitar presenciar la ceremonia. A la mañana siguiente, pese al dolor, aprovechando un momento de soledad en la casa, se acerca a la dekchoucha para mirar a la desposada, que le parece más hermosa que ella. Apenada, comienza a llorar y, al regresar su marido y encontrarla en ese estado, se interesa por su malestar, respondiéndole que la aarousa le había hecho la higa ${ }^{28}$ (Chimenti, 2009: 438; Malina, 2001) y le exige que actúe en consecuencia. Si El-Arbi da satisfacción a la petición de su esposa, al considerar que la desposada, carente del conocimiento y la formación de la Lalla, debido a su juventud, le debía respeto.

Lalla Zouleima se siente reconfortada, pero al día siguiente, nuevamente, movida por la curiosidad de ver a Noufissa, la encuentra engalanada de forma que da muestra del gran amor que su esposo le profesa. Ebria de celos y cólera, Lalla Zouleima se arranca el cabello, se araña la cara y grita. Las nagafat (las esclavas negras) y las helafat (asistentes del tribunal), asustadas acuden a su auxilio. Lalla Zouleima acusa a la cheriqua de haberla atacado, soliviantando a las mujeres contra esta, en su ánimo de venganza, pero, una vez calmada, decide esperar el regreso de su marido para que dirima en este conflicto. En la espera, se acercan a la deckchoucha para proferir insultos contra la cheriqua, a la que acusan de insultarlas y de abalanzarse contra ellas para pegarlas.

A su llegada, Si El-Arbi, tras ser informado de todo lo sucedido por Lalla Zouleima, las nagafat y las helafat, insta a todas a ir ante el pachá para que la cheriqua pague por el delito cometido. Dado su sentido de justicia, decide visitar, previamente, a la coespoesa para conocer su versión de los hechos. Si El-Arbi, en compañía de las mujeres de la casa, tras entrar en la deckchoucha, desvela a la

\footnotetext{
${ }^{28} \mathrm{O}$ mano itifálica. En el original, «m'a fait le doigt». Según la antropología cultural, hacer la higa corresponde al gesto apotropaico del dedo pulgar o medio entre los demás de la palma para rechazar el mal de ojo, con un valor de bufa o escarnio.
} 
desposada, ante el horror de todas las presentes, al descubrir que no es más que una larga y esbelta haidoura o tina de barro, cubierta de ricos ropajes, tumbada sobre el suntuoso lecho, entre cojines bordados en oro y bajo tapices de Damasco.

\section{Estructura discursiva del cuento «La Cadia»}

La estructura discursiva del cuento guarda estrecha relación con la connotación de la palabra testigo que integra el título y viene anunciada con la introducción «Je te raconte, Ne crains rien, Ne crains pas les génies» ${ }^{29}$ (Chimenti, 2009: 434), donde se evoca las tres principales tradiciones de las que bebe la autora:

(1) El cuento: en sus variantes populares de la tradición oriental (persa, árabe y turco) y de la qișṣa fāsīya (originario de Fez) (El Fasi \& Dermenghem, 1926: 35) y la variante culta de il racconto europeo del Ottocento (Guglielmi, 2005; Pellizzi, 2002; 2002);

(2) El género bio-bibliográfico árabe e islámico oriental medieval y andalusí o las țabaqāt y 'ilm al-rîyâl (compendios bio-bibliográficos y hagiográficos de los gremios de hombres doctos), con su supestructura comunicativa (Gumperz y Hymes, 1972; Van Dijk, 1980) propia: el jabar y.

(3) los $\bar{a} d \bar{a} b$ al-quḍat o compendios sobre las normas de conducta de los jueces medievales.

Elisa Chimenti transmite de cada una de estas tres tradiciones elementos que permiten la hibridación y el mestizaje, dando un resultado innovador. Así toma:

- Del cuento popular oriental, la tradición escrita de Les Mille et une nuits de Antoine Galland;

- Del ciclo de la qiș̣a fāsīya, la oralidad magrebí puesta en boca de las mujeres y la descripción estilizada de usos y costumbres de la alta sociedad de Fez de origen andalusí y de sus instituciones;

- Del género biográfico oriental y andalusí medieval, la superestructura comunicativa y discursiva del jabar, combinada con los compendios sobre las normas de conducta de los jueces orientales medievales y andalusíes o ādāb al-qudāt, que le permiten construir la configuración de los personajes y la trama, vinculándola a su estructura semántica con su función específica original, dado el proceso de recepción de este tipo de obras entre el propio colectivo de ulemas en el medievo y

- Todo ello, bajo la cornice narrative del racconto (Pellizzi, 2002), con el cual nos introduce el marco narrativo y la estructura de final abierto del que carecen tanto la qișșa fāsīya como el jabar oriental medieval y el andalusí.

\footnotetext{
${ }^{29}$ La evocación a los «génies» (los genios o djinoun/ŷunūn) nos lleva al recurso de la magia negra por hacerse amar y lograr aumentar el sentimiento de la pasión sensual por uno mismo en la persona amada. Es un componente literario muy común en el cuento popular marroquí y, especialmente en el de Fez (qișsa fāsīya) del que el presente cuento es deudor.
} 
Brevemente, en primer lugar, describimos los rasgos esenciales del jabar, al ser la estructura tradicional islámica exógena a la tradición europea del cuento moderno y contemporáneo que la autora elige y adapta para la construcción de los personajes, conforme a las normas de los jueces o ādāb al-quḍāt. Seguidamente, exponemos la adaptación de la qiș̣a fāsīya a la cornice narrative del racconto del Ottocento, que la autora opera en este cuento híbrido resultante.

\section{El Jabar y los ädäb al-quḍāt o Normas de Conducta de los Jueces}

Elisa Chimenti innova el género del cuento haciendo de él un «continuum, come un'area in cui si confrontano diversi usi, percezioni e temperie culturali» (Pellizzi, 2002), al insertar la estructura narrativa medieval árabe e islámica del jabar o noticia bio-biliográfica. Estas noticias (ajbār) constituyen la estructura básica para la elaboración de las obras genealógicas y hagiográficas islámicas dentro de lo que se podría denominar el género biográfico en contexto islámico. Están destinadas a la elaboración de la identidad de una personalidad musulmana relevante e introducidas por un epígrafe, correspondiente a una palabra-clave, normalmente un gentilicio, un patronímico o un apodo (laqab), por el que es conocido el personaje. Estas noticias constan de una breve introducción histórica, geográfica, administrativa o etimológica, a modo de aclaración de la duda que suscite el epígrafe entre los ulemas destinatarios de todo el Dār al-islām (Pascual Barea, 1997). Paralelamente, al constituir un evento comunicativo textual entre los miembros del grupo determinado (Gumperz y Hymes, 1972) de los ulemas, suele tener una función ilustrativa y el fin ejemplarizante y/o simbólico de dar veracidad a la revelación de las sagradas escrituras y a la tradición profética del islam, a través de las cadenas de transmisión consideradas fiables y veraces (Rodríguez Mediano, 1995: 23).

Se utiliza en la elaboración de las biografías clasificadas por categorías jerarquizadas de generaciones de tradicionistas (muḥadditūna), juristas (quḍāt), exégetas coránicos (mufassirūna), entre otros gremios, al priorizar la descripción de las genealogías de sus transmisores, a través de las representaciones estereotipadas de personalidades concretas de memoriones, lexicógrafos, exégetas, jurisconsultos y, junto a ellos, los jueces, por citar los más comunes. Esta forma de establecer listados permite, para evitar homonimias, individualizar a cada sabio, aportar datos diferenciadores y anécdotas privadas, normalmente, hagiografías probatorias, donde se selecciona material muy determinado y escaso, que terminan convirtiéndose en un topos (Rodríguez Mediano, 1995: 23).

La impronta del jabar quedará configurada con el genealogista e historiador cordobés Ibn al-Faraḍi (m.1012) (1988; Ávila-Marín, 1997: 47-48), al ceñir la biografía a una estructura narrativa ${ }^{30}$, en la que, sin ubicación fija, suele estar inserto antes de la fecha de la muerte del personaje, pero es independiente, prescindible, trasplantable y modificable según el autor.

\footnotetext{
30 El esquema estandarizado contempla 1. la inclusión del nombre completo del personaje; 2. el gentilicio; 3. el credo religioso; 4. la familia a la que pertenece y la fecha de nacimiento; 5 . la parte del nombre
} 
Su doble condición de estructura narrativa y de superestructura comunicativa y discursiva potencia el cuento como evento comunicativo eficaz para la interacción textual, en su calidad de acto lingüístico, al registrar un nivel particular de discurso que requiere a todos los miembros del grupo un saber idiomático concreto.

«La Cadia», emulando un jabar, recrea una escena doméstica de dos cadíes en el contexto institucional de las normas de conducta de los jueces, recogidas en los compendios de los $\bar{a} d \bar{a} b$ al-quḍat. De entre los temas que este género aborda, destaca el concerniente a los requisitos que deben reunir los jueces musulmanes para el ejercicio de sus funciones (Fyzee, 1964: 408):

The cadi should be God-fearing; he should be just; he should not follow his passions, nor favour any party, nor fear any person. He must obey God, hope for divine favour and save himself from punishment. The cadi must not carry on trade, nor should he take loans; nor be bad tempered and quarrelsome. People should have no doubt as to his virtue ('iffa), sobriety (salâhiyya), wisdom and knowledge of law and traditions. He must be strict in the matter of religion, but not be harsh of speech. He should not exercise his powers in anger, or when he is weakened by non-obligatory fasts. He should not perform his judicial functions under the influence of hunger or thirst, nor when he is moved by lust, nor when his mind is distracted by heat or cold. Legally, he must be eligible to give evidence in a court of law; such a person is called ' $a d l$. That is, he must be a Muslim and not a heretic, who has reached the age of majority, is of sane mind, is free (hurr, as distinguished from a slave) and of irreproachable character. In all the schools, except the Hanafi, the cadi should be a man, a woman being ineligible.

Adaptar al cuento la estructura del jabar supone una serie de innovaciones, entre las que destaca, en primer lugar, la sustitución de una línea de transmisión de hombres doctos relevantes conforme la tradición culta de la que bebe, por otra compuesta de dos mujeres, la autora y su supuesta vecina y amiga Mennana, desplazando así a los sabios al rol de meros cándidos ignorantes: «Les oulama assuraient que la science des femmes manquait de profondeur, qu'elle était toute de surface, qu'un cerveau féminin était incapable d'invention [Ô candides et naïfs oulama !] et même de perfectionnement» (Chimenti, 2009: 434-435), a los que agrupa en una masa anónima, como si de un gremio de artesanos se tratase, a la altura de los «marchands d'étoffes, bijoutiers et attarat $^{31} \gg$ (434).

En segundo lugar, elige como protagonista de la ejemplificación del correcto cumplimiento de las normas de conducta de los jueces del islam a una mujer, hecho

\footnotetext{
Footnote 30 (continued)

equivalente al apellido y el alias o apodo (laqab); 6. los maestros; 7. dos discípulos; 8. los viajes de estudios (rihla) en búsqueda de sus maestros; 9. las disciplinas religiosas en las que se forma; 10. las calificaciones recibidas; 11 . la fecha de la muerte y 12. la fuente de la que toma la información.

31 Perfumistas.
} 
poco común en el género genealógico y hagiográfico, pero constatado documentalmente (Ávila-Marín, 1997).

En tercer lugar, el jabar suele describir una escena familiar que desvela una información relevante del juez biografiado que lo valide o invalide como titular de su cargo institucional. La autora invierte esta tradición del género en la reconstrucción de la identidad de la biografiada y deja entrever que los protagonistas representan un caso de matrimonio islámico parigual $(k a f \bar{a} \text { ' ' } i a)^{32}$, el más deseable para quien aspire a ser designado juez (Chimenti, 2009: 435-436):

Or, à cette époque, il était à Fes, certain cadi riche et sage, qui avait épousé la fille d'un ouzir ${ }^{33}$, belle et chaste personne, profondément versée dans le droit musulman [...] le cadi, [...] il paraissait satisfait de son mariage et amoureux de sa cadia. Zouleima, d'ailleurs, était très belle, bonne, charitable et traitait son mari d'égal et non point d'inférieur, [...] Souvent, le soir, alors qu'accroupis sur les metareb ${ }^{34}$, ils sirotaient le thé à la menthe, les deux cadis discutaient avec mesure et politesse.

Este matrimonio homógamo cimenta la jerarquización social (Carmona González, 1987), gracias a que ambos poseen las cualidades requeridas conforme a la doctrina del matrimonio islámico: Lalla Zouleima «belle et chaste personne» (Chimenti, 2009: 435) responde al modelo teórico de la virtud femenina como mujer digna de alabanza, en tanto que mujer casada, y cumple con sus obligaciones conyugales y profesionales, pese a ejercer fuera del hogar (436):

Après les heures de la mehakma Madame El-Arbi rentrait chez elle, surveillait son ménage, donnait des ordres à ses esclaves, qui l'adoraient et offrait un thé quotidien à ses helafat qui lui étaient entièrement dévouées. Modeste dans son habillement, Zouleima ne portait que des caftans aux couleurs sobres et des fines mousselines de laine blanche, comme il sied à une cadia qui se respecte,

y $S i$ El-Arbi, un «certain cadi riche et sage» (435) estaba enamorado de su esposa, quien «d'ailleurs, était très belle, bonne, charitable et traitait son mari d'égal et non point d'inférieur» (436).

Ambos comparten diversas cualidades que los adecúan para el ejercicio de la judicatura, como el pertenecer a un estatus socioeconómico elevado y parejo que les abstendrá de pedir préstamos o ayuda financiera a particulares para cubrir sus necesidades; el no ser proclives a bromear con la gente, al estar obligados a mantener una adustez no proveniente del malhumor y el ser humildes, Así, Elisa Chimenti retrata a un Si El-Arbi en los siguientes términos (436): «Les oulama et les riches bourgeois s'étaient bien un peu moqués de Si El-Arbi [...] Mais le cadi, au courant des critiques et des moqueries, ne disait mot et souriait dans sa belle barbe de roi assyrien». Y de Lalla Zouleima nos aclara que es una «femme sévère», (436).

\footnotetext{
32 Doctrina de la igualdad social en el matrimonio.

33 Ministre du sultan.

34 Matelas-divans.
} 
No obstante, como establecen los $\bar{a} d \bar{a} b$ al-quḍat han de ser personas sociables con la moderación suficiente como para que no sean muy numerosas las personas que frecuenten su hogar, así como tampoco el extenuarse teniendo audiencia, siendo necesario el saber dosificar su dedicación laboral con el tiempo de ocio (437):

Souvent, le soir, alors qu'accroupis sur les metare $b^{35}$, ils sirotaient le thé à la menthe, les deux cadis discutaient avec mesure et politesse. Le cadi prétendait que, malgré leurs grandes qualités, les femmes manquaient d'impartialité et faisaient de mauvais magistrats, elles jugent avec leur cœur et non pas avec leur cerveau, assurait-il.

El matrimonio, en su figura contractual conforme a la ley islámica (nikāhn) (al-Gazālī, 1963) nos da la clave para entender las respectivas estratagemas ideadas por los protagonistas en la resolución del conflicto que plantea.

$\mathrm{Si}$ El-Arbi, convencido de que el hombre es poseedor de un sentido connatural de justicia y ecuanimidad mayor que el de la mujer y que su criterio es más aproximado a la realidad que el de su esposa la cadia, le anuncia que va a casarse en segundas nupcias con una bella y cultivada joven, conforme a la ley. Es decir, no hay cláusula de monogamia, propia de los contratos firmados inter pares, que evite la tetragamia y que permita a Lalla Zouleima divorciarse de su marido. De ahí que ella recurra a acusar a la segunda esposa de un comportamiento inadecuado contra ella, dado que no puede culpar a su esposo de infidelidad o comportamiento reprobable ante un juez en una demanda de divorcio.

En la actitud de ambos, se muestran dos características remarcables que ayudan a esclarecer parte del final abierto del cuento. La primera, el amor mutuo que se profesan los dos protagonistas, circunstancia esta poco común en los ajbār. Si El-Arbi, «satisfait de son mariage et amoureux de sa cadia» (Chimenti, 2009: 435), evita denigrar a su esposa casándose con otras mujeres y adquiriendo nuevas esclavas para cubrir sus necesidades sexuales. Lalla Zouleima enamorada de su marido, «était jalouse -mais ne dit rien [...] s'enfuit dans la cour pour pleurer à son aise» [...] «Elle aurait bien voulu se plaindre à ses esclaves et à ses adjointes, mais elle n'osait blâmer son mari qui, d'après la loi, avait droit à quatre épouses et à un nombre illimité de concubines» (437).

La segunda, la observancia de las normas de conducta de los jueces que nos muestra a Si El-Arbi como un juez con «específica aptitud» (Carmona González, 1987: 235) para su cargo, dada su templanza en el carácter que le evita juzgar a su libre albedrío y actuar con gradación, conforme a la participación de las mujeres de la casa involucradas-las helafat y las nagafat -, dos categorías sociales inferiores al servicio directo de la cadia (Chimenti, 2009: 439):

Avec de malédictions et des cris, parlant toutes à la fois, ces dames accusèrent Lalla Noufissa d'avoir insulté Madame la cadia. Si El-Arbi les fit taire et interrogea sa femme.

35 Matelas-divans. 
Cependant je vous demanderai à toutes de prêter serment sur le tombeau vénéré de Moulay Idriss.

- L'aarousa t'a-t-elle frappée ?

- Oui, dit-elle, un peu honteuse.

- Tes adjointes étaient-elles présentes lorsque cela est arrivé ?

- Oui, crièrent-elles, que notre religion nous soir défendue si nous n'avons pas vu comme nous te voyons maintenant, ta nouvelle épouse frapper notre cadia.

- Nous prêterons serment, crièrent encore ces dames !...

- Allons voir la coupable, conseilla le cadi, car il est juste d'entendre les deux parties.

Suivi de la cadia et de ses témoins, Si El-Arbi pénétra dans la dekchoucha, ouvrit la fenêtre de la chambre et dévoila la mariée.

Esta amable plasmación sigue la tradición marcada por el cuento fāsī (El Fasi $\&$ Dermenghem, 1926), que la autora adapta al final abierto posible en il racconto europeo del Ottocento italiano, poco común en la qișsa fāsīya y en el jabar.

\section{La qișșa o cuento tradicional popular oriental, la qișșa fāssīya magrebí e il racconto europeo}

Elisa Chimenti integra este jabar en el ciclo de la tradición oral del cuento $f \bar{a} s \bar{\imath}$, cuya transmisión suele depender de narradoras y realizarse en entorno familiar, aunque sea conocida por buena parte de los miembros de la comunidad de donde proviene (El Fasi \& Dermenghem, 1926: 35-36). Estos cuentos fasíes suelen describir con lujo de detalle:

la vie quotidienne, des institutions, coutumes et idées des pacifiques et de raffinés habitants de la cité de Moulay Idriss ${ }^{36}$. Nous y retrouverons les maisons, les portes, les corporations, les hammams ${ }^{37}$ et les mosquées, les écoles de garçons et des filles, les souks ${ }^{38}$, les métiers de toutes sortes, le Sultan et son Makhzen ${ }^{39}$, les Mokhaznis ${ }^{40}$, les adoul ${ }^{41}$, les cadis, les musiciens et les instruments de musique, les muezzins ${ }^{42}$ appelant aux cinq prières, le tribunal

\footnotetext{
36 Así conocida la ciudad de Fez, en honor al nombre de su fundador.

37 Los baños públicos.

38 Los zocos.

39 Sistema de gobierno implantado por el sultán en Marruecos.

40 Guardias, agentes de seguridad del sultán de Marruecos.

41 Notarios.

42 Almuédanos.
} 
du Sultan, les zarzaïa ${ }^{43}$, les laveuses, les grilleurs de saucisses, et les jardiniers djebala $^{44}$, les âniers criant balek $^{45}$ et leurs bêtes chargées d’un double sac plein de farine, sel, charbon, crottin pour chauffer les bains, marchandises, etc.

En su mayoría, de origen argelino o marroquí, destilan la influencia oriental de Les Mille et Une Nuits y de la producción literaria árabe y su relación con la religión y la magia, por medio de la mención a los génies (genios) o djinoun (diablos) ${ }^{46}$ (El Fasi \& Dermenghem, 1926: 29; Menon \& Tamburlini, 1998: 98).

Por su parte, il racconto breve del Ottocento aporta a «La Cadia» elementos comunes a la qișsa oriental, inexistentes en la qișșa fāsīya, como la analepsis, por medio del recuerdo de hechos, directamente, a través de los personajes y la inserción de la autora al inicio del cuento, creando una cornice narrativa o historia marco, con la que logra crear un racconto nel racconto (Battista Tomassini, 1991), que, dada la brevedad que marca este género, la acción se limita a un único evento de conflicto, anunciado en la primera frase de la introducción «Je te raconte», que anticipa la mencionada anacronía (Pellizzi, 2002). Este anuncio sitúa a la autora en el papel de narradora omnisciente, al insertarse como parte del mismo, para exponernos el marco narrativo de manera sucinta (Chimenti, 2009: 434, 435): «Les femmes de siècles passés, au dire de Mennana, ma voisine et amie, ne ressemblaient guère à celles $\mathrm{d}^{\prime}$ aujourd hui $[\ldots]$ Or, à cette époque, il était à Fes, certain cadi [...]».

No obstante, el principal elemento que toma prestado la autora del racconto breve es el final inconcluso y abierto a la participación del lector, para que pueda construir, bajo su criterio, un desenlace acorde a sus expectativas, al proponer un juego literario que le permite abstenerse de responder a las exigencias de un público lector con un desenlace que, probablemente, no le satisfaga plenamente.

Con la qișsa fāsīya, il racconto comparte el análisis de los ambientes, de los personajes y de las situaciones en una trama no compleja. La elección de los protagonistas, provenientes del estadio más elevado sociocultural y económicamente hablando, y, especialmente, la de los personajes femeninos secundarios dan buena muestra de la tradición cuentística local híbrida y mestiza que rescata Elisa Chimenti, conformada, según Mohammed El Fasi y Emile Dermenghem, «d’un répertoire collectif courant» en un «cicle spécial», «purement fasis», narrados «par des amateurs, presque toujours des femmes» que «ne sont pas nécessairement purement berbères et ont subi certainement des influences arabes», de numerosas «influences

\footnotetext{
43 Porteadores o mozos de cuerda.

44 Campesinos de la montaña.

45 Uso dialectal del correspondiente en árabe estándar ¡Bālu- $k$ ! Es el aviso dado por los porteadores callejeros en los zocos equivalente al castellano ¡Cuidado, atención!, para que la gente abra paso y, así, evitar pararse, debido al peso excesivo de la carga. Su reiteración constante genera una melodía monocorde.

46 Elisa Chimenti, desde muy joven se dedica a estudiar las creencias, tradiciones, costumbres preislámicas árabes y hebreas (https://www.elisachimenti.org/oeuvres_inedites.html) y, muy particularmente, la creencia en los $\hat{y} u n \bar{u} n$ (djinoun). Es la única escritora que ha dedicado un ensayo a la figura de ' $\overline{\mathrm{A}}$ 'iša Qandīša (Aicha Kandicha), considerada popularmente una ŷ̀n (djin) o demonio, objeto de superstición en contexto islámico, y del que se extrae la conclusión de que no es más que una variante de la diosa Astarté.
} 
orientales»y, especialmente con «emprunts de détail à la littérature écrite arabe; et ces traits communs peuvent n'être eux-mêmes que des emprunts au folklore universel» (1926: 12-14).

\section{La connotación de la invención léxica «Cadia»}

La hibridación estructural del cuento «La Cadia» que acabamos de mostrar, contribuye a comprender la connotación que la autora aporta a la invención léxica que articula en su título y, especialmente, la adaptación del jabar, como suprestructura comunicativa y discursiva, dado que, conforme a la proposición lexicológica de Georges Matoré (1948), Elisa Chimenti no considera la palabra como un elemento aislado, sino un reflejo de la sociedad.

La invención léxica «cadia» no carece de fundamento histórico. La doctrina islámica (Carmona, 1987; Milliot, 1953; Schacht, 1964), producto del despertar científico del contacto del islam con el derecho romano, persa y hebraico, contribuyó a la creación de cuatro escuelas doctrinales, en el marco de la sunna, entre las cuales la hanafìya la única doctrina (madhab) sunní que considera a las mujeres candidatas elegibles para ejercer la función de cadí (Tillier, 2009: 8):

In theory, Hanafīs even recognized a woman's right to be a $q \bar{a} d \underline{\bar{\imath}}$. Indeed, in

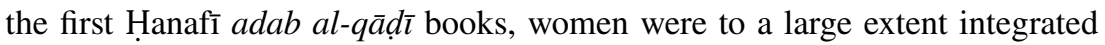
into the court. They appeared in this literature both as plaintiffs and as judicial auxiliaries.

Entre sus jurisconsultos más eminentes, este madhab cuenta con el imán iraquí AbūBakr al-Jașșāf (s. IX d.C.) (1978), autor de tratado Adab al-qā ḍ̄ sobre las normas de los jueces (Tillier, 2009: 5), donde recoge el término técnico de sitt quḍat (auxiliar judicial) para referirse a la mujer agente de los juzgados, pero no el de cadía o jueza $(q \bar{a} d \bar{l} y a)$. Es decir, como realidad jurídica bajo los abasíes iraquíes, en lo que documentalmente consta, sitt quḍāt denota el escalafón máximo para una mujer en el cadiazgo y, siempre, en rango inferior al de un hombre con su misma formación. A un segundo nivel de la sitt quḍāt, encontramos a las halīfāt, auxiliares tanto del $q \bar{a} d \underline{\imath}$ como de la sitt quḍāt, encargadas de tomar juramento a las litigantes mujeres (Tillier, 2009: 5-7).

En el cuento, Elisa Chimenti recoge esta última figura, las halīfāt, con el valor de «adjointes» de la cadia, tal y como aclara la nota a pie de página de la edición consultada (2009: 436, n.15): «Après les heures de la mehakma ${ }^{47}$ Madame ElArbi rentrait chez elle, surveillait son ménage, donnait des ordres à ses esclaves, qui l'adoraient et offrait un thé quotidien à ses helafat qui lui étaient entièrement dévouées».

La autora respeta la jerarquía piramidal recogida en los tratados de las normas de conducta de los jueces y la plasma en los grupos de hablantes que participan en el cuento, pertenecientes, a su vez, a tres estamentos socioculturales:

47 Tribunal. 
(1) Los protagonistas Si El-Arbi, el cadí, Lalla Zouleima La Cadia adila, ambos vinculados con la justicia, la religión y la cultura, dado que en el islam clásico no se disgrega el conocimiento científico ('ilm) de la religión ( $d \bar{\imath} n$ ), ni de la jurisprudencia ("ilm al-fiqh) a la hora de impartir justicia. Los miembros de la comunidad que adquieren dicho conocimiento lo hacen a través de la palabra escrita en árabe coránico o fuṣhà, marcando el nivel más alto de formación cultural.

(2) En un nivel intermedio, encontramos a las helafat o auxiliares de la cadia, que suelen ser las adjuntas en los tribunales que dirimen litigios en los que se ven involucradas las mujeres como litigantes,

(3) En un tercer nivel, las nagafat o mujeres encargadas de organizar las bodas, que suelen ser mujeres de raza negra («négresses») (Chimenti, 2009: 438) y de condición esclava y,

(4) En último lugar, la aaroussa/cheriqua o coesposa Lalla Noufissa que no habla, dado que no existe, al ser una mera tina cubierta de ricos ropajes tumbada en un lecho nupcial.

Las reglas de uso y las variables lingüísticas que presentan los personajes muestran el modelo estratificatorio (López Morales, 2004: 106), el mercado lingüístico, las redes sociales y el modo de vida doméstico de la aristocracia fās̄ medieval, constatables en la variante arcaizante del dialectal del francés norteafricano pied-noir/ pataouète en el que está redactado. Los préstamos del árabe y de beréber funcionan en el cuento como variaciones lingüísticas que no producen diferencias de significado ni afectan a la intención comunicativa de la autora, puesto que siempre ofrece su equivalente en francés, en aposición o en nota a pie de página, por lo que los cultismos y los realia quedan rescatados (Mur, 2020: 5) de la oralidad. Así, el cuento deviene herramienta válida de análisis de los factores diferenciales -sexo, edad, raza, religión, origen, cultura profesión y estatus civil- que registra, a través del lenguaje, los retratos psicológicos y físicos de los personajes.

Desde el punto de vista estilístico, esta mezcla lingüística toma distancia con respecto a los «clichés orientalisants» (Kohn-Pireux, 2009: 194), propios de la corriente literaria ${ }^{48}$ en la que la narratología francesa encuadra a nuestra autora (Noiray, 1996: 14) y, dado que ella es miembro integrante de la comunidad sobre la que escribe, «es en esta tónica que cobra importancia la obra de Elisa Chimenti» (Mur, 2020: 4).

\footnotetext{
48 Compuesta por autores adheridos al orientalismo etnográfico, entre los que destacan a los hermanos Jérôme (1874-1953) y Jean (1877-1952) Tharaud, ambos amigos del Residente General (1912-1925) de la República Francesa en Marruecos Louis Hubert Lyautey. Tienen en su haber una extensa producción conjunta, entre los que destacamos La Fête arabe (1912) y Rabat ou les Heures marocaines (1919). Un tercer autor destacado de esta corriente es François Bonjean (1884-1963) y su obra Les Confidences d'une fille de la nuit (1939) o Au Maroc en roulotte (1950).
} 


\section{Conclusión}

Conforme a los postulados lexicológicos de Georges Matoré (1948) que sustentan nuestra hipótesis de investigación, la invención léxica cadia, en su calidad de palabra-testigo que visualiza un hábitat y unas formas de vida en contexto islámico, evoca una época concreta, como una totalidad, a modo de síntesis significativa aplicable a lo existente. Contribuye a la conceptualización del conjunto de actividades humanas que este cuento -híbrido y mestizo- ilustra, combinando estructuras narrativas orientales y europeas y siguiendo la tradición hagiográfica que inspira el género biográfico islámico medieval. Cadia, pese a evocar una institución sustentada por la vía masculina, designa a la mujer formada para el desempeño de la judicatura, a título subsidiario del cadí -sitt qud̄āt -. Por lo tanto, estamos ante una palabra que atestigua lo que consta en las fuentes documentales oficiales islámicas, que, en lengua árabe, tanto en tiempos de la conformación del islam hasta la época de la publicación del cuento, es inexistente, oficialmente, de ahí el recurso de la autora a una invención en una variante dialectal del francés norteafricano que adopta un cultismo árabe, para reflejar el estado político, jurídico-social y religioso-moral tanto de la sociedad medieval a la que se retrotrae como de la coetánea a la autora.

\section{Anexo}

«a Cadia.

Je te raconte,

Ne crains rien, ne crains pas les génies.

Les femmes de siècles passés, au dire de Mennana, ma voisine et amie, ne ressemblaient guère à celles d'aujourd'hui. Dédaignant les riches caftans de soie à ramages d'or, les transparentes ferrajiat ${ }^{49}$, les sebani ${ }^{50}$ à longues franges, les bijoux, les subtils parfums et les fards qui embellissent, elles recherchaient la science « du berceau à la tombe» suivant le conseil du Hadith ${ }^{51}$. « La science, disaient-elles, vaut mieux que les richesses et le savoir est un plus grand trésor que les diamants et les perles.» Aussi, trouvait-on à Fès et ailleurs au Maroc, des femmes médecins, des femmes oukilat $t^{52}$ et même des cadiat $^{53}$.

Marchands d'étoffes, bijoutiers et attarat $^{54}$ faisaient faillite et les couturières, sous prétexte qu'elles avaient gardé de leur ancien métier une certaine habileté à manier les ciseaux et les épingles, s'étaient improvisées critiques littéraires.

Cependant, les hommes, au lieu d'applaudir au sérieux et à la modestie de leurs épouses, prétendaient que, moins coquettes, les femmes n’étaient plus aussi jolies,

\footnotetext{
49 1.Tuniques légères. Nota de la edición.

50 2. Foulards. Nota de la edición.

51 Con mayúscula en el original.

52 3. Avocates. Nota de la edición.

53 4. Femmes cadi, juges. Nota de la edición.

54 5. Parfumeurs. Nota de la edición.
} 
que la nature, souvent, a besoin des secours de l'art et que, sans parfums, ni fards, les lallat ${ }^{55}$ étaient moins désirables.

«Leurs lèvres, disaient-ils, ont désappris les gracieux sourires et leurs yeux, à force de fixer les manuscrits anciens et modernes, ont perdu tout éclat».

Les oulama ${ }^{56}$ assuraient que la science des femmes manquait de profondeur, qu'elle était toute de surface, qu'un cerveau féminin était incapable d'invention [Ô candides et naïfs oulama !] et même de perfectionnement.

Ils citaient le proverbe arabe: «La beauté de l’homme est dans son intelligence et l'intelligence de la femme est dans sa beauté.»

Les bourgeois se moquaient de leurs douces moitiés. Ils disaient qu'elles lais-

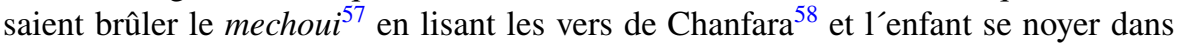
la citerne alors qu'elles cherchaient la sagesse dans les livres des philosophes. Ils exagéraient, évidemment, avec une mauvaise foi bien masculine, et oubliaient qu'ils avaient souvent accusé leurs compagnes de frivolité et blâmé leur amour immodéré de la parure. «Hélas ! disaient-ils, nous étions bien mal venus à nous plaindre de la coquetterie de nos femmes: lorsqu'elles pensaient à leurs chiffons, elles nous épargnaient les conseils de leur science récemment acquise et ne prétendaient point régenter leurs maris et sauver l'humanité.»

Ainsi les maris se plaignaient; ainsi ils critiquaient dans les harems somptueux, d'où elles s'étaient évadées, lasses de n'être que de vaines idoles, vivant pour le plaisir de l’homme, de l’homme exigeant, sévère, indulgent à ses seuls défauts.

Or, à cette époque, il était à Fes, certain cadi riche et sage, qui avait épousé la fille d'un ouzir $^{59}$, belle et chaste personne, profondément versée dans le droit musulman et s honorant du titre de cadia auquel les Fassi ${ }^{60}$ pourtant frondeurs, avaient ajouté celui de adila $^{61}$.

Les oulama et les riches bourgeois s'étaient bien un peu moqués de Si El-Arbi, qui était allé chercher son épouse dans la phalange des chaqiat $^{62}$. (Le mot féministe n'étant pas encore connu c'est ainsi qu'on nommait les femmes aux idées avancées.) Mais le cadi, au courant des critiques et des moqueries, ne disait mot et souriait dans sa belle barbe de roi assyrien: il paraissait satisfait de son mariage et amoureux de sa cadia. Zouleima, d'ailleurs, était très belle, bonne, charitable et traitait son mari d'égal et non point d'inférieur, bien qu'elle prétendit que les hommes manquaient de subtilité et de discernement, et qu'ils se laissaient influencer plus facilement que les femmes.

Après les heures de la mehakma ${ }^{63}$ Madame El-Arbi rentrait chez elle, surveillait son ménage, donnait des ordres à ses esclaves, qui l'adoraient et offrait un thé quotidien à ses helafat ${ }^{64}$ qui lui étaient entièrement dévouées.

\footnotetext{
55 6. Dames. Nota de la edición.

56 7. Savants. Nota de la edición.

57 8. Rôti. Nota de la edición.

58 9. Poète arabe. Nota de la edición.

59 10. Ministre du sultan. Nota de la edición.

60 11. Originaires de Fès. Nota de la edición.

61 12. Juste. Nota de la edición.

62 13. Malheureuses. Nota de la edición.

63 14. Tribunal. Nota de la edición.

64 15. Adjointes. Nota de la edición.
} 
Modeste dans son habillement, Zouleima ne portait que des caftans aux couleurs sobres et des fines mousselines de laine blanche, comme il sied à une cadia qui se respecte. Seul, un merveilleux diamant, enchassé ${ }^{65}$ dans un cercle d'argent, brillait à l'annulaire de cette femme sévère, qui paraissait témoigner d'un certain goût pour les bijoux.

Souvent, le soir, alors qu'accroupis sur les metareb ${ }^{66}$, ils sirotaient le thé à la menthe, les deux cadis discutaient avec mesure et politesse. Le cadi prétendait que, malgré leurs grandes qualités, les femmes manquaient d'impartialité et faisaient de mauvais magistrats, elles jugent avec leur cœur et non pas avec leur cerveau, assurait-il.

Madame la cadia répliquait que Monsieur son époux se trompait, que les femmes étaient non seulement plus impartiales, mais infiniment plus droites et justes que les hommes, qui se laissent aisément séduire par un beau visage.

- Voyons, disait-elle, à crime pareil, donneriez-vous une peine égale à deux femmes dont l'une serait jeune et belle et l'autre vieille el laide ?

- Certes, disait le cadi.

- Non, répondait sa femme.

Si El-Arbi, un jour, n'y tenant plus, dit qu'il pariait un manuscrit ancien d'un prix inestimable, contre un plat de couscous, qu'il convaincrait Madame la cadia d'injustice et de mensonge. Le pari fut accepté et on ne discuta plus.

À quelque temps de là, le cadi informa Zouleima qu'elle aurait bientôt une cheri$q u a^{67}$, une femme charmante, jeune, très belle et assez cultivée. La cadia pâlit—elle aimait son mari et en était jalouse-mais ne dit rien.

Étonné de son silence, Si El-Arbi demanda:

- Ne suis-je pas dans mon droit?

- Certes, dit Zouleima, et elle s'enfuit dans la cour pour pleurer à son aise.

Le lendemain, les préparatifs de la noce furent commencés. Si El-Arbi consultait sa femme à tout propos, pour les draperies de la chambre nuptiale, pour l'ornement de la dekchoucha ${ }^{68}$, pour les bijoux et les riches parures qu'il destinait à la nouvelle épouse de 1'ammaria ${ }^{69}$, les nagafat ${ }^{70}$ se rendirent chez Si El-Arbi et préparèrent la chambre nuptiale, qu'elles garnirent de haitis $^{71}$, de soie, de rideaux tissés d'or, de tapis de Rabat et d'innombrables coussins brodés. Au fond de la pièce, elles

\footnotetext{
65 Posible errata.

66 16. Matelas-divans. Nota de la edición.

67 17. Coépuse. Nota de la edición.

68 18. Couche nuptiale. Nota de la edición.

69 19. Le jour du mariage. Nota de la edición.

70 20. Négresses qui président aux fêtes du mariage. Nota de la edición.

71 21. Tenture murale. Nota de la edición.
} 
installèrent la dekchoucha, dans laquelle les mariés devaient passer leur première nuit.

La cadia s'enferma dans sa chambre, et, sous prétexte qu'elle était lasse et malade, refusa de manger et de voir son mari.

Le soir, l'aarousa ${ }^{72}$ arriva dans une somptueuse ammaria $^{73}$ couronnée de jasmins et suivie d'un cortège nombreux. Les nagafat portèrent la mariée dans la chambre nuptiale où son époux se hâta de la rejoindre.

Zouleima pleura toute la nuit. Elle aurait bien voulu se plaindre à ses esclaves et à ses adjointes, mais elle n’osait blâmer son mari qui, d'après la loi, avait droit à quatre épouses et à un nombre illimité de concubines.

Lorsque Si El-Arbi sortit de la maison, Zouleima, se cachant de ses femmes, alla regarder la nouvelle mariée. Elle vit au fond de la dekchoucha, une forme svelte couverte de riches vêtements et crut apercevoir dans l'ombre deux yeux moqueurs.

«Cette femme est plus jeune et plus belle que moi», pensa-t-elle, et elle se mit à pleurer.

Son mari arriva et lui demanda la cause de sa douleur.

- Votre nouvelle épouse, dit la cadia m’a « fait le doigt» ${ }^{74}$. Consentirez-vous à ce qu'elle me manque de respect?

- Non, dit le cadi, elle est plus jeune que vous, ne possède votre science ni votre sagesse, et vous doit le respect.

Lalla Zouleima se retira peu consolée par les mots de son mari.

Lorsque le lendemain Si El-Arbi sortit de l'appartement de Noufissa, la nouvelle mariée, la cadia vint de nouveau contempler sa rivale. Celle-ci avait une toilette plus splendide encore que celle de la veille et de nouveaux bijoux qui témoignaient du grand amour de l'époux. Ivre de jalousie et de colère, Zouleima s'arracha les cheveux, laboura son beau visage de ses ongles et poussa des cris déchirants.

Négresses et adjointes accoururent efrayées ${ }^{75}$.

- Voyez, dit-elle, ce que m’a fait la cheriqua: non contente de m’́insulter, elle s'est approchée de la fenêtre et, me prenant par les cheveux, m’a déchiré le visage.

- Assistance de Dieu... serait-il-possible !...

- Cette fille du péché a osé injurier la meilleure, la plus savante de femmes !

- La plus belle, ajoutèrent les négresses qui, sans doute, connaissaient mieux leur maîtresse.

- Puissions-nous être regardées comme des esclaves du péché, si nous ne tirons une prompte vengeance de cette maudite.

\footnotetext{
72 22. Nouvelle marie. Nota de la edición.

73 23. Palanquin. Nota de la edición.

74 24. Geste malséant. Nota de la edición.

75 Posible errata.
} 
- Non, dit Madame El-Arbi, attendons l'arrivée de mon époux. Il jugera et choisira entre nous deux. Après une telle injure, je ne saurais demeurer ici, à moins que $S i$ El-Arbi ne répudie Lalla $^{76}$ Noufissa.

- Bien, dirent adjointes et négresses, attendons Sidi.

- Elles attendirent un moment, puis, poussées par la curiosité, approchèrent de la chambre de la coupable, regardèrent à l'intérieur et poussèrent des exclamations indignées.

- Elle rit, la malheureuse !

- Elle se moque de nous.

- Vois comme elle remue les lèvres, elle nous insulte.

- Ô chienne, fille de chienne, que Dieu maudisse tes parents !

- Elle se lève, elle veut vous battre, que l'enfer soit sur elle !

Le cadi arriva, alors que les adjointes se sauvaient dans la cour.

- Qu'y a-t-il donc et pourquoi courez-vous ?

Avec de malédictions et des cris, parlant toutes à la fois, ces dames accusèrent Lalla Noufissa d'avoir insulté Madame la cadia.

Si El-Arbi les fit taire et interrogea sa femme.

- L'aarousa t'a-t-elle frappée?

- Oui, dit-elle, un peu honteuse.

- Tes adjointes étaient-elles présentes lorsque cela est arrivé ?

- Oui, crièrent-elles, que notre religion nous soir défendue si nous n'avons pas vu comme nous te voyons maintenant, ta nouvelle épouse frapper notre cadia.

- Ceci est grave, dit Si El-Arbi, nous allons nous rendre chez le pacha et j'espère que vous ne refuserez pas de témoigner en faveur de Lalla.

- Nous irons chez le pacha et même chez notre seigneur le Sultan s’il le faut!

- Bien, dit encore le cadi, je vous crois.

- Cependant je vous demanderai à toutes de prêter serment sur le tombeau vénéré de Moulay Idriss.

- Nous prêterons serment, crièrent encore ces dames !...

- Allons voir la coupable, conseilla le cadi, car il est juste d'entendre les deux parties.

Suivi de la cadia et de ses témoins, Si El-Arbi pénétra dans la dekchoucha, ouvrit la fenêtre de la chambre et dévoila la mariée.

Horreur ! Sur le lit somptueux, parmi les coussins brodés d'or, sous les tentures de Damas, il n'y avait qu'une longue et svelte haidoura, une simple cruche couverte de riches vêtements».

76 25. Madame. Nota de la edición. 
Funding Open Access funding provided thanks to the CRUE-CSIC agreement with Springer Nature.

Open Access This article is licensed under a Creative Commons Attribution 4.0 International License, which permits use, sharing, adaptation, distribution and reproduction in any medium or format, as long as you give appropriate credit to the original author(s) and the source, provide a link to the Creative Commons licence, and indicate if changes were made. The images or other third party material in this article are included in the article's Creative Commons licence, unless indicated otherwise in a credit line to the material. If material is not included in the article's Creative Commons licence and your intended use is not permitted by statutory regulation or exceeds the permitted use, you will need to obtain permission directly from the copyright holder. To view a copy of this licence, visit http://creativecommons.org/licenses/by/4.0/.

\section{Referencias}

Allen, R. (2011). Rewriting literary history: The case of Moroccan fiction in Arabic. The Journal of North African Studies, 16(3), 312-315.

Ascha, Gh. (1989). Du statut inférieur de la femme en islam. París: Éditions L’Harmattan.

Ávila, M. L., \& Marín, M. (Eds.). (1997). Biografías y género biográfico en el occidente islámico. Estudios Onomásticos-biográficos de al-Andalus VIII. CSIC.

Battista Tomassini, G. (1991). Il racconto nel racconto. Analisi teorica dei procedimenti d'inserzione narrativa (Strumenti di ricerca). Roma: Bulzoni.

Benhlal, M. (2005). Le collège d'Azrou. La formation d'une élite berbère civile et militaire au Maroc (1927-1959). París-Aix-en-Provence: Éditions KARTHALA-IREMAN.

Bénouis, M. (1974). Parlez.vous sabir ... ou pied-noir? The French Review, 47(3), 578-582.

Blau, J. (1965). The emergence and linguistic background of Judeao-Arabic. A study of the origins of Middle Arabic. Oxford University Press.

Blau, J. (1981). The state of research in the field of the linguistic study of Middle Arabic. Arabica, 28(2-3), 187-203.

Blau, J. (1988). Studies in Middle Arabic and its Judeao-Arabic variety. The Magnes Press, The Hebrew University.

Bouhdiba, A. (1975). La sexualité en Islam, París : PUF.

Bousquet, G. H. (1966). L'éthique sexuelle de l'Islam. París : Maisonneuve et Larose.

Bunis, D. M., Chetrit, J., \& Sahim, H. (2002). Jewish languages enter the modern era. In The Jews of the Middle East and North Africa in modern times, ed. Reeva Spector Simon, Michael Menachem Laskier, and Sara Reguer (pp. 113-42). Nueva York: Columbia University Press.

Cañete Aranda, Ma . D. (1998). Repercusiones de las orientaciones panislamistas y panarabistas en el nacimiento del nacionalismo político en el norte de Marruecos. Hespéris-Tamuda, XXXVI, 111-133.

Carmona González, A. (1987). Los adab al-quḍāt o normas de conducta del juez islámico. Homenaje al profesor Juan Torres Fontes 1, Murcia, Universidad de Murcia-Academia Alfonso el Sabio, pp. $235-243$.

Chimenti, E. (2009). Anthologie. Marruecos : Éditions du Sirocco \& Senso Unico Éditions.

Cortés, J. (Ed.). (1999). El corán. Editorial Herder.

Dakhlia, J. (2008). Lingua franca. Histoire d'une langue métisse en Méditerranée. París: Actes Sud.

Del Moral, C. (1994). Contribución a la historia de la mujer a partir de las fuentes literarias andalusíes. La sociedad medieval a través de la literatura hispanojudía. VI Curso de Cultura Hispanojudía y Sefardí de la Universidad de Castilla-La Mancha. Cuenca: Ediciones de la Universidad Castilla-La Mancha, pp. 101-120.

Fasi (El-), M., \& Dermenghem, E. (1926). Contes fasis. París : F. Rieder et C $\mathrm{C}^{\mathrm{ie}}$, éditeurs.

Elías de Tejada, F. (1960). Cerdeña hispánica. Sevilla: Medicines Montejurra.

Ferrando, I. (2001). Introducción a la historia de la lengua árabe: Nuevas perspectivas. Zaragoza.

Fyzee, AAA. (1964). «The «Adab al-Qadi» in Islamic Law». Malaya Law Review, 6(2), 406-416.

Gaudefroy-Demombynes, M. (1946). Les institutions musulmanes. Flammarion.

Gazālī, A. H.. (Al-). (1963). Iḥyā’' al-'ulūm al-dīn, libro XX. L. Zolondek (Trad.). Leiden: E. J. Brill. Le livre des bons usages en matière de mariage (Extrait de 1'Ihiya' 'Ouloúm ed-Dín ou: Vivification des Sciences de la foi), traduction française annotée par Léon Bercher \& Georges-Henri Bousquet (1989), París : Librairie d’Amérique et d’Orient A. Maisonneuve.

González González, I. (2010). Escuela e ideología en el Protectorado español en el Norte de Marruecos (1912-1956). Toledo, Universidad de Castilla La Mancha. 
Guglielmi, G. (2005). Un’idea di racconto. Bolletino '900, 1-2. http://www3.unibo.it/boll900/numeri/ 2005-i/.

Gumperz, J. J., \& Hymes, D. (1972). Directions in sociolinguistics: The ethnography of communication. Nueva York: Holt, Rinehart \& Winston.

Ibn al-Faraḍi, A. W. (1988) Ta'rīj 'ulamā' wa-l-ruwā li-l-'ilm bi-l-Andalus 2 vols. El Cairo: Maktaba al-Jāniŷ̄i.

Jașșāf (al-), A. B. (1978). Adab al-qāệ̀, ed. Farḥāt Ziyāda. El Cairo: The American University in Cairo Press.

Kohn-Pireux, L. (2009). Variations autour du récit-cadre des Mille et une nuits: La version Mardrus. Les Mille et une nuits et le récit oriental. En Espagne et en Occident. París: L'Harmattan, pp. 193-211.

Lachiri, N. (1993). La imagen de la mujer en las fuentes literarias andalusíes, Dra. Celia del Moral y la Dra. $\mathbf{M}^{\mathrm{a}}$ Jesús Viguera Molins (Dirs.). Madrid: Universidad Complutense.

Lachiri, N. (2002). La mujer andalusí en los repertorios biográficos. Miscelánea De Estudios Árabes y Hebraicos Sección Islam, 51, 39-52.

Laskier, M. M. (1983). Aspects of the activities of the alliance Israélite Universelle in the Jewish communities of the Middle East and North Africa: 1860-1918. Modern Judaism, 3(2), 147-171. https:// www.jstor.org/stable/1396078.

López Morales, H. (2004). Sociolingüística. Gredos.

Malina, B. J. (2001). The «New Testament» world: Insights from cultural anthropology. 3a ed. Louisville: Westminster John Knox Press.

Marchetti, M. (2017). Elisa Chimenti: Un ponte tra Europa e Mediterraneo. In Marco Severini (Ed.). La scelta del viaggio. Venecia: Marsilio Editori, pp. 139-150.

Matoré, G. (1953). La méthode en lexicologie. Domaine française. Marcel Didier.

Menon, M. \& Tamburlini, M. P. (1998). Elisa Chimenti. Archivio. Tánger, https://www.elisachimenti.org/ texte/biographie_elisa_doc/biographie_elisa_doc1.pdf.

Miège. J.-L. (1962). Le Maroc et l'Europe. 1822-1906. Rabat : Editions La Porte.

Milliot, L., \& Blanc, F.-P. (1953). Introduction à l'étude du droit musulman. París : Recueil Sirey.

Nataf, G., Graille, B., \& Boucherit, A. (2002). Proverbes libyens recueillis par Roger Chambard. Avec un index arabe-français/français-arabe. Éditions Kartala.

Noiray, J. (1996). Littératures francophones, I. Le Maghreb. París: Belin.

Pascual Barea, J. (1997). Del latín tardío *montecellu al topónimo andaluz Montejil. Gades, 22, 607-619.

Paye, L. (1992). Introduction et évolution de l'Enseignement Moderne au Maroc (Des origines jusqu'à 1956). Mohammed Benchekroun (Ed.). Rabat: Imprimérie al-Risāla.

Pellizzi, F. (2002). Sul racconto. Bollettino '900, 1-2. http://www3.unibo.it/boll900/numeri/2002-i/.

Pilia, E. (2013). Opere inedite. Volume secondo. Cagliari: CUEC Editrice.

Quṭb, M. (1960). Šubuhāt ḥawl al-islām. El Cairo: Maktaba Wahba, $4^{\text {a }}$ (Ed.).

Rivet, D. (1999). Le MAROC de Lyautey à Mohammed V, le double visage du Protectorat. París: Denoël.

Rodríguez Mediano, F. (1995). Familias de Fez (ss. XV-XVII). Madrid: CSIC.

Romaine, S. (1996). El lenguaje en la sociedad. Una introducción a la sociolingüística. Ariel.

Schacht, J. (1964). An introduction to Islamic Law. Oxford University Press.

Schuchardt, H. (1909). Die Lingua franca. Zeitschrift Für Romanische Philologie, 33, 441-461.

Sobh, M. (2002). Historia de la literatura árabe clásica. Cátedra.

Thomas De Antonio, Cl. (1989). El nombre propio en la lengua árabe. Miscelánea de Estudios Árabes y Hebraicos. Sección Islam, 38(1), 337-357.

Tillier, M. (2009). Women before the qāḍī under the Abbasids. Islamic Law and Society. Brill Academic Publishers, 16, 280-301. halshs-00582725. https://halshs.archives-ouvertes.fr/halshs-00582725/document.

Tillion, G. (1966). L’harem et les cousins. París : Le Seuil.

Tobi, Y. (2010). Farḥ̄, Eliezer. In Encyclopedia of Jews in the Islamic World. Norman A. Stillman (Ed.), Leiden: Brill, https://referenceworks.brillonline.com/entries/encyclopedia-of-jews-in-the-islamicworld/farhi-eliezer-SIM_0007630.

Van Dijk, T. A. (1980). An interdisciplinary study of global structures in discourses, interaction and cognition. Macroestructures. Hillsdale (Nueva Jersey): Lawrence Associates.

Wensinck, A. J. (1978). Khabar. In Encyclopédie de l'Islam, IV, Leiden: E. J. Brill, p. 928.

Publisher's Note Springer Nature remains neutral with regard to jurisdictional claims in published maps and institutional affiliations. 